\title{
Photoluminescence of Germanium(II), Tin(II), and Lead(II) Chloride Complexes in Solution
}

\author{
Hans Nikol, Alexander Becht, and Arnd Vogler* \\ Institut für Anorganische Chemie, Universität Regensburg, Universitätsstrasse 31, \\ W-8400 Regensburg, Germany
}

Received March 13, 1992

\begin{abstract}
The absorption and emission spectra of $\mathrm{GeCl}_{3}{ }^{-}, \mathrm{SnCl}_{3}{ }^{-}, \mathrm{PbCl}_{3}{ }^{-}$, and $\mathrm{PbCl}_{4}{ }^{2-}$ in acetonitrile were recorded. In addition, emission quantum yields and lifetimes were determined. The emitting excited states are of the metalcentered sp type and originate from the ${ }^{3} \mathrm{P}$ state of the free $\mathrm{s}^{2}$ ions. It is suggested that the complex ions which have trigonal-pyramidal $C_{3 v}\left(\mathrm{MCl}_{3}{ }^{-}\right)$and seesaw $C_{2 v}\left(\mathrm{PbCl}_{4}{ }^{2-}\right)$ structures in the ground state rearrange toward trigonalplanar $D_{3 h}$ and tetrahedral $T_{d}$ geometries, respectively, in their sp excited states.
\end{abstract}

\section{Introduction}

Emission spectroscopy is of overwhelming importance in the field of photophysics and photochemistry. With regard to coordination compounds, the application of this technique has been essentially restricted to transition metals, ${ }^{1}$ while very little is known about the luminescence of main group metal complexes. ${ }^{2}$ This is rather surprising in view of the fact that it has been known for 50 years that simple halide complexes of metals with an $\mathbf{s}^{2}$ electron configuration are luminescent in solution. ${ }^{3}$ Recently, we started a systematic investigation of the emission spectra of such complexes in solution. First results were obtained with the anions $\mathrm{MCl}_{4}$ - and $\mathrm{MCl}_{6}{ }^{3-}\left(\mathrm{M}=\mathrm{Sb}^{3+}, \mathrm{Bi}^{3+}\right) .{ }^{4-6}$ The present study, which deals with the complexes $\mathrm{MCl}_{3}{ }^{-}$and $\mathrm{MCl}_{4}{ }^{2-}$ of the group IV metal ions $\mathrm{Ge}^{2+}, \mathrm{Sn}^{2+}$, and $\mathrm{Pb}^{2+}$, is a significant extension of this work. $\mathrm{Sn}^{2+3,7}$ and $\mathrm{Pb}^{2+3,7,8}$ are known to be emissive in aqueous solution. However, the emitting excited states have rarely been characterized. In addition, the emitting species have not been identified unambiguously, since complicated equilibria exist in aqueous solution. In order to avoid the complications in aqueous medium, acetonitrile was used as solvent for the present study. Due to the low coordinating ability of acetonitrile, well-defined chloro complexes of $\mathrm{Ge}^{2+}, \mathrm{Sn}^{2+}$, and $\mathrm{Pb}^{2+}$ are formed in this solvent.

Not only is the present investigation interesting in its own right but our observations are also important for other areas. Since $\mathrm{MCl}_{3}-(\mathrm{M}=\mathrm{Ge}, \mathrm{Sn}, \mathrm{Pb})$ is isoelectronic with carbanions $\mathrm{CR}_{3}{ }^{-}$, our findings may be related to the yet unknown excitedstate properties of these organic intermediates. ${ }^{9}$ In addition, the intriguing emission behavior of the homonuclear $\mathrm{Sn}^{2+}$ cluster compound $\left[\mathrm{Sn}_{6} \mathrm{O}_{4}\left(\mathrm{OCH}_{3}\right)_{4}\right]^{10}$ and polynuclear metal complexes which contain a bond between a transition metal and $\mathrm{Ge}^{2+}, \mathrm{Sn}^{2+}$, and $\mathrm{Pb}^{2+}$ has attracted much attention in recent years. ${ }^{11,12}$ Accordingly, the study of simple complexes of these $\mathrm{M}^{2+}$ ions

(1) (a) Balzani, V.; Carassiti, V. Photochemistry of Coordination Compounds; Academic Press: New York, 1970. (b) Concepts of Inorganic Photochemistry; Adamson, A. W., Fleischauer, P. D., Eds.; Wiley-Interscience: New York, 1975. (c) Ferraudi, G. J. Elements of Inorganic Photochemistry; Wiley-Interscience: New York, 1988.

(2) Vogler, A.; Paukner, A.; Kunkely, H. Coord. Chem. Rev. 1990, 97, 285.

(3) Pringsheim, P.; Vogels, H. Physica 1940, 7, 225

(4) Nikol, H.: Vogler, A. J. Am. Chem. Soc. 1991, 113, 8988.

(5) Blasse, G; Vogler, A. Inorg. Chim. Acta 1990, 170,149

(6) Vogler, A.; Paukner, A. Inorg. Chim. Acta 1989, 163, 207

(7) Sill, C. W.; Peterson, H. E. Anal. Chem. 1949, 21, 1266.

(8) Narayanaswamy, R.; Mayne, P. J.; Kirkbright, G. F. J. Inorg. Nucl. Chem. 1978, 40, 129 .

(9) Kunkely, H.; Vogler, A. Unpublished results on the photophysics of tricyanomethanide, $\mathrm{C}(\mathrm{CN})_{3}^{-}$

(10) Kunkely, H.; Vogler, A. Chem. Phys. Lett. 1991, 187, 609.

(II) (a) Luong, J. C.; Faltynek, R. A.; Wrighton, M. S. J. Am. Chem. Soc 1979, 101, 1597. (b) Luong, J. C.; Faltynek, R. A.; Wrighton, M. S. J. Am. Chem. Soc. 1980, 102, 7892 . should be of great value for the understanding of the more complicated polynuclear complexes. Finally, it should be mentioned that there is a remarkable photochemistry of chloro complexes of $\mathrm{Sn}^{2+} .3,13-15$ The photooxidation of $\mathrm{Sn}^{2+}$ can be applied for electroless metal deposition in the electronics industry. ${ }^{14}$ The present investigation serves also to characterize the reactive excited states which were not identified in previous studies.

\section{Experimental Section}

Materials. $\left[\mathrm{NEt}_{4}\right] \mathrm{GeCl}_{3}$ and $\left[\mathrm{NEt}_{4}\right] \mathrm{SnCl}_{3}$ were prepared according to a published procedure. ${ }^{16}\left[\mathrm{NEt}_{4}\right] \mathrm{PbCl}_{3}$ was synthesized by a procedure similar to that of the preparation of $\left[\mathrm{NH}_{4}\right] \mathrm{PbCl}_{3} .{ }^{17}$ Acetonitrile was spectrograde.

Spectroscopy. Absorption spectra were measured with an Uvikon 860 double-beam spectrophotometer. Emission spectra were obtained on a Hitachi 850 spectrofluorimeter which was equipped with a Hamamatsu 928 photomultiplier. The luminescence spectra were corrected for monochromator and photomultiplier efficiency. Absolute emission quantum yields were determined by comparison of integrated emission intensity of $\mathrm{GeCl}_{3}^{-}, \mathrm{SnCl}_{3}^{-}, \mathrm{PbCl}_{3}^{-}$, and $\mathrm{PbCl}_{4}^{2-}$ with that of quinine sulfate in 0.5 $\mathrm{M} \mathrm{H}_{2} \mathrm{SO}_{4}\left(\lambda_{\max }=452 \mathrm{~nm} ; \phi=0.546\right)^{18}$ at identical conditions such as exciting wavelength, optical density, and apparatus parameters.

\section{Results}

The absorption spectra of the complex ions $\mathrm{MCl}_{3}-$ in $\mathrm{CH}_{3} \mathrm{CN}$ were characterized by UV bands (Figures 1-3, Table I). Upon addition of chloride to solutions of $\mathrm{GeCl}_{3}{ }^{-}$and $\mathrm{SnCl}_{3}-$ in $\mathrm{CH}_{3} \mathrm{CN}$, the absorption spectra did not change. In typical experiments, the complex concentrations were approximately $10^{-4} \mathrm{M}$ and chloride was added up to $0.5 \mathrm{M}$. It follows that $\mathrm{Ge}^{2+}$ and $\mathrm{Sn}^{2+}$ do not form complexes $\mathrm{MCl}_{x}{ }^{(x-2)-}$ with $x>3$ under these conditions. On the contrary, the addition of $\mathrm{Cl}^{-}$to solutions of $\mathrm{PbCl}_{3}$ - was accompanied by spectral variations, including clear isosbestic points at 284 and $255 \mathrm{~nm}$ (Figure 3). Finally, the original band was completely replaced by the new absorption. According to an analysis of the spectral changes and their dependency on the concentration of added chloride, the new band at $\lambda_{\max }=294 \mathrm{~nm}$ was attributed to $\mathrm{PbCl}_{4}{ }^{2-}$ (Table I). The equi-

(12) (a) Balch, A. L.; Olmstead, M. M.; Oram, D. E.; Reedy, P. E.; Reimer, S. H. J. Am. Chem. Soc. 1989, 111, 4021. (b) Balch, A. L.; Catalano V. J.; Chatfield, M. A.; Nagle, J. K.; Olmstead, M. M.; Reedy, P. E. J. Am Chem Soc 1991,113 1252 (c) Balch, A L.: Neve, F.; Olmstead, M. M. Inorg. Chem. 1991, 30, 3395.

(13) Shinohara, N.; Inoue, M. Bull. Chem. Soc. Jpn. 1989, 62, 730

(14) (a) D'Amico, J. F.; De Angelo, M. A.; Henrickson, J. F.; Kenney, J. T. Sharp, D. J. J. Electrochem. Soc. 1970, 118, 1695. (b) D'Amico, J. F.; Litt, F. A.; De Angelo, M. A. J. Electrochem. Soc. 1972, 119, 956.

(15) (a) Haring, R. C.; Walton, J. H. J. Phys. Chem. 1933, 37, 133. (b) Haring, R. C. Walton, J. H. J. Phys. Chem. 1933, 37, 375

(16) Parshall, G. W. Inorg. Synth. 1974, 15, 222.

(17) Gutmann, V. Nedbalek E Monatsh. Chem 1958, 89, 130

(18) Demas, J. N.; Crosby, G. A. J. Phys. Chem. 1971, 75, 991. 


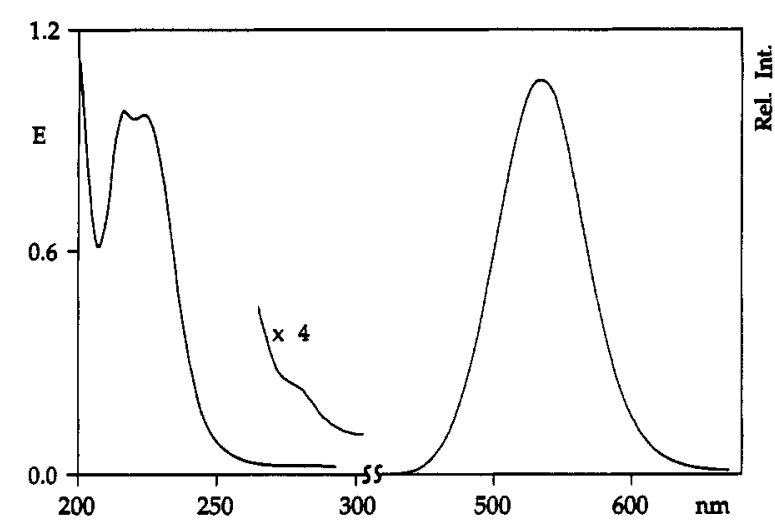

Figure 1. Electronic absorption (left side) and emission (right side) spectra of $\left[\mathrm{NEt}_{4}\right] \mathrm{GeCl}_{3}$ in acetonitrile at room temperature $(1-\mathrm{cm}$ cell). Absorption: $1.94 \times 10^{-4} \mathrm{M}$. Emission: $7.43 \times 10^{-4} \mathrm{M}, \lambda_{\text {exc }}=250 \mathrm{~nm}$, intensity in arbitrary units.

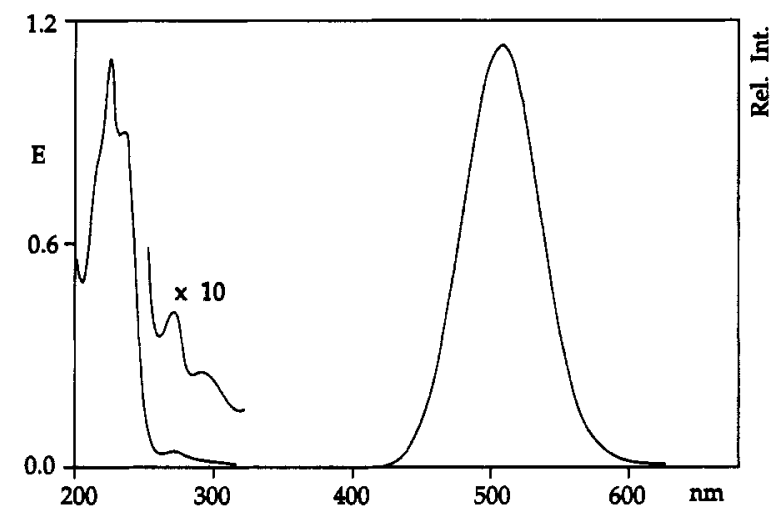

Figure 2. Electronic absorption (left side) and emission (right side) spectra of $\left[\mathrm{NEt}_{4}\right] \mathrm{SnCl}_{3}$ in acetonitrile at room temperature $(1-\mathrm{cm}$ cell). Absorption: $6.0 \times 10^{-5} \mathrm{M}$. Emission: $7.0 \times 10^{-4} \mathrm{M}, \lambda_{\text {exc }}=250 \mathrm{~nm}$, intensity in arbitrary units.

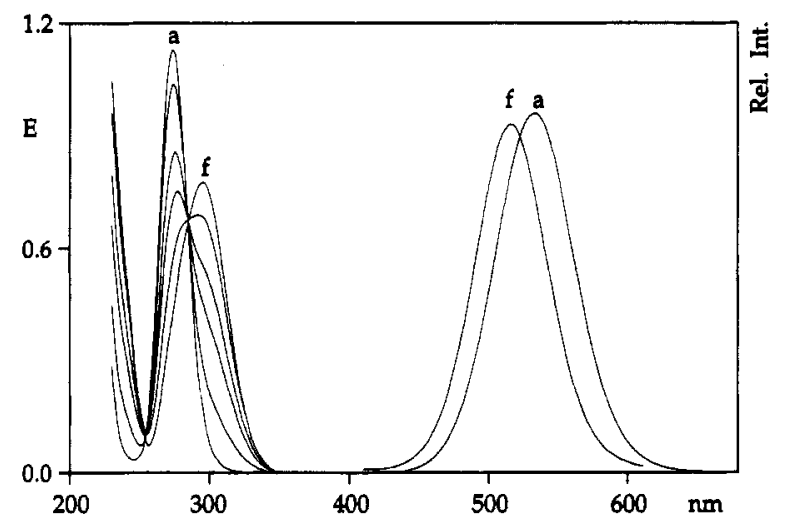

Figure 3. Electronic absorption (left side) and emission (right side) spectra of $\left[\mathrm{NEt}_{4}\right] \mathrm{PbCl}_{3}$ in acetonitrile at room temperature $(1-\mathrm{cm}$ cell). Absorption: $1.8 \times 10^{-4} \mathrm{M}$ without $\left[\mathrm{NEt}_{4}\right] \mathrm{Cl}$ (a) and in the presence of $0.016,0.043,0.066,0.124$, and $0.240 \mathrm{M}\left[\mathrm{NEt}_{4}\right] \mathrm{Cl}$ (f). Emission: 2.25 $\times 10^{-4} \mathrm{M}$ without $\left[\mathrm{NH}_{4}\right] \mathrm{Cl}$ (a) and in the presence of $1 \mathrm{M}\left[\mathrm{NEt}_{4}\right] \mathrm{Cl}(\mathrm{f})$, $\lambda_{\text {exc }}=250 \mathrm{~nm}$, intensity in arbitrary units.

librium constant $\left(\mathrm{PbCl}_{3}{ }^{-}+\mathrm{Cl}^{-} \rightleftharpoons \mathrm{PbCl}_{4}{ }^{2-}\right)$ was rather small ( $K$ $\left.=8.5 \times 10^{-2} \mathrm{~L} \mathrm{~mol}^{-1}\right)$.

Upon light absorption, all four complex ions in $\mathrm{CH}_{3} \mathrm{CN}$ showed a green luminescence at room temperature (Figures 1-3, Table I). The excitation spectra matched the absorption spectra rather well. The emission lifetimes could be determined only for $\mathrm{PbCl}_{3}-$ and $\mathrm{PbCl}_{4}{ }^{2-}$, while $\mathrm{GeCl}_{3}$ - and $\mathrm{SnCl}_{3}{ }^{-}$did not yield reproducible results. The lifetime measurements of the latter ions were apparently hampered by their photochemical instability. In deaerated solutions the luminescence was rather intense. In the presence of oxygen, the emission intensity was much lower (Table I).
Table I. Absorption and Emission Data for $\mathrm{MCl}_{3}{ }^{-}(\mathrm{M}=\mathrm{Ge}, \mathrm{Sn}$, $\mathrm{Pb})$ and $\mathrm{MCl}_{4}{ }^{2-}(\mathrm{M}=\mathrm{Pb})$ in $\mathrm{CH}_{3} \mathrm{CN}$ at Room Temperature

\begin{tabular}{|c|c|c|c|c|}
\hline & $\mathrm{GeCl}_{3}^{-}$ & $\mathrm{SnCl}_{3}^{-}$ & $\mathrm{PbCl}_{3}^{-}$ & $\mathrm{PbCl}_{4}^{2-}$ \\
\hline \multicolumn{5}{|c|}{ Absorption } \\
\hline 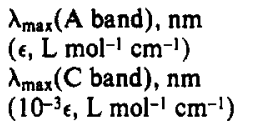 & $\begin{array}{c}280 \\
(30) \\
218,225 \\
(4.9,4.8)\end{array}$ & $\begin{array}{c}292,272 \\
(300,700) \\
216,226,236 \\
(12.9,17.3,14.0)\end{array}$ & $\begin{array}{c}273 \\
(8100) \\
205 \\
(22.8)\end{array}$ & $\begin{array}{c}294 \\
(8200)\end{array}$ \\
\hline \multicolumn{5}{|c|}{ Emission } \\
\hline$\lambda_{\max }, \mathrm{nm}$ & 535 & 510 & 538 & 518 \\
\hline $10^{2} \phi$ (air-saturate & $a$ & 3.1 & 2.4 & 5.4 \\
\hline $10^{2} \phi$ (argon-saturated) & 8.1 & 6.8 & 15.9 & 14.4 \\
\hline Stokes shift, $\mathrm{cm}^{-1}$ & 17000 & $15900^{6}$ & 18000 & 14700 \\
\hline $\begin{array}{l}\text { emission lifetime, } \\
\tau(\text { argon-saturate }\end{array}$ & $c$ & $c$ & $17 \pm 1^{d}$ & \\
\hline
\end{tabular}

$\tau$ (argon-saturated), $\mu \mathrm{s}$

a Owing to rapid thermal oxidation, reliable quantum yields could not be determined. ${ }^{b}$ Based on the average of both absorption maxima of the A band. ${ }^{\circ}$ Owing to photochemical instability, reliable lifetimes could not be determined. ${ }^{d}$ Single-exponential decay.

\section{Discussion}

The electronic spectra of $\mathrm{s}^{2}$ ions doped into solid matrices such as halides and oxides have been investigated extensively. ${ }^{19,20}$ In all cases, the basic pattern of the absorption spectra is quite similar. The low-energy bands can be assigned to $s \rightarrow p$ transitions. An $s^{2}$ ion has a ${ }^{1} \mathrm{~S}_{0}$ ground state and ${ }^{3} \mathrm{P}_{0},{ }^{3} \mathrm{P}_{1},{ }^{3} \mathrm{P}_{2}$, and ${ }^{1} \mathrm{P}_{1}$ sp excited states. The ${ }^{1} \mathrm{~S}_{0} \rightarrow{ }^{3} \mathrm{P}_{0}$ transition is strongly forbidden and not observed in absorption. The spectrum is characterized by the $A$ $\left({ }^{1} \mathrm{~S}_{0} \rightarrow{ }^{3} \mathrm{P}_{1}\right)$, B $\left({ }^{1} \mathrm{~S}_{0} \rightarrow{ }^{3} \mathrm{P}_{2}\right)$, and $\mathrm{C}\left({ }^{1} \mathrm{~S}_{0} \rightarrow{ }^{1} \mathrm{P}_{1}\right)$ bands with decreasing wavelength. The energy of these transitions depends on the metal and is modified by the matrix, but the essential features of the spectrum do not change. 19,20 The absorption bands of $\mathrm{MCl}_{3}{ }^{-}$and $\mathrm{MCl}_{4}{ }^{2-}$ in $\mathrm{CH}_{3} \mathrm{CN}$ (Table I) were assigned by analogy to the spectra of the $\mathrm{M}^{2+}$ ions in halide matrices. ${ }^{19-21}$ In any case, the longest-wavelength absorption is always the $A$ band.

Generally, the emission of $\mathrm{s}^{2}$ ions in solid matrices originates from the ${ }^{3} \mathbf{P}_{1}$ level. ${ }^{19,20}$ There is little doubt that the luminescence of $\mathrm{MCl}_{3}{ }^{-}$and $\mathrm{MCl}_{4}{ }^{2-}$ (Figures 1-3, Table I) can also be assigned to the ${ }^{3} \mathbf{P}_{1} \rightarrow{ }^{1} \mathrm{~S}_{0}$ transition. The rather long emission lifetime is in agreement with a spin-forbidden transition. However, considerable singlet-triplet mixing facilitated by the heavy-atom effect of the $s^{2}$ ions does certainly occur.

In summary, the emission and longest-wavelength absorption bands of $\mathrm{MCl}_{3}{ }^{-}$and $\mathrm{MCl}_{4}{ }^{2-}$ can be reliably assigned to a metalcentered transition which involves the $s$ and $p$ metal orbitals. However, such a simple model which is based on the electronic transitions of the free ions does not account for other spectral features such as the Stokes shift. The structures of the complex ions in the ground and excited states obviously must be included for a more appropriate description.

According to the VSEPR model developed by Gillespie and Nyholm, ${ }^{22}$ all $\mathbf{A X}_{3}$ and $\mathbf{A X}_{4}$ molecules or ions with a $\mathrm{s}^{2}$ central atom are trigonal-pyramidal $\left(C_{3 v}\right)$ and butterfly (or seesaw) $\left(C_{2 v}\right)$ structured, respectively. The $\mathrm{MCl}_{3}-$ and $\mathrm{MCl}_{4}{ }^{2-}$ complexes in acetonitrile certainly also exist as these structures. This assumption is supported by far-infrared and Raman spectral data of solutions of $\mathrm{GeX}_{3}{ }^{-23}$ and $\mathrm{SnX}_{3}{ }^{-24}$ respectively, and solid-state structures of $\mathrm{GeCl}_{3}{ }^{-, 25-27} \mathrm{SnCl}_{3}{ }^{-, 27-29}$ and $\mathrm{PbCl}_{3}{ }^{-}$as determined

(19) Ranfagni, A.; Mugnai, D.; Bacci, M.; Viliani, G.; Fontana, M. P. Adv. Phys. 1983, 32, 823.

(20) (a) Blasse, G. Prog. Solid State Chem. 1988, 18, 79. (b) Blasse, G. Rev. Inorg. Chem. 1983, 5, 319.

(21) Fukuda, A.; Inohara, K.; Onaka, R. J. Phys. Soc. Jpn. 1964, 19, 1274

(22) (a) Gillespie, R. J.; Nyholm, R. S. Q. Rev. Chem. Soc. 1957, 11, 339. (b) Gillespie, R. J. Molecular Geometry; Van Nostrand Reinhold: London, 1972. (c) Gillespie, R. J.; Hargittai, I. The VSEPR Model of Molecular Geometry; Allyn and Bacon: Boston, MA, 1991.

(23) Poskozim, P. S.; Stone, A. L. J. Inorg. Nucl. Chem. 1970, 32, 1391

(24) Goldstein, M.; Tok, G. C. J. Chem. Soc. A 1971, 2303.

(25) Messer, D. Z. Naturforsch. 1978, 33B, 366.

(26) Thiele, G.; Rotter, H. W.; Schmidt, K. D. Z. Anorg. Allg. Chem. 1987, 545,148 


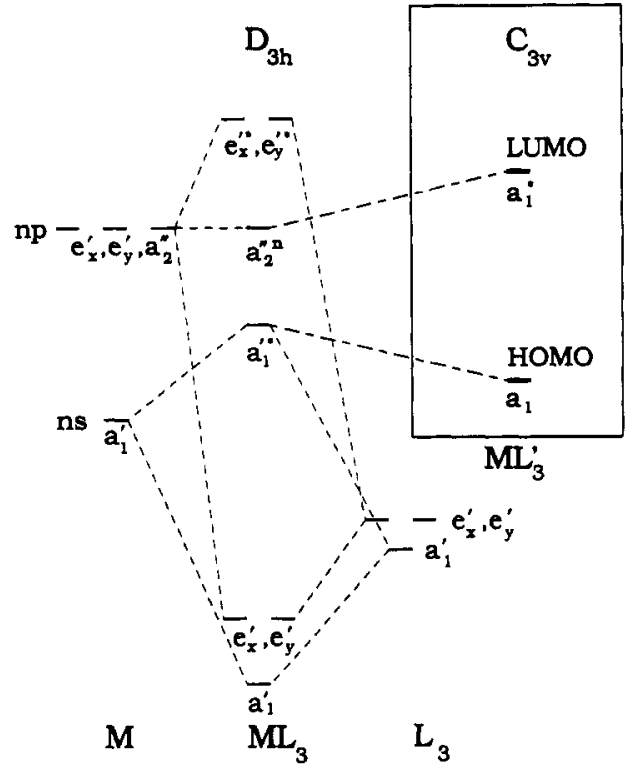

Figure 4. Qualitative $\mathrm{MO}$ scheme of $\mathrm{MCl}_{3}-(\mathrm{M}=\mathrm{Ge}, \mathrm{Sn}, \mathrm{Pb})$ in $D_{3 h}$ (trigonal-planar) and $C_{3 v}$ (trigonal-pyramidal) symmetry (Walsh diagram). $\pi$ orbitals of the ligands are omitted.

by X-ray crystallography. Many solids contain discrete trigonalpyramidal $\mathrm{MCl}_{3}$ - ions. In some cases polymeric structures with bridging chloride are formed. ${ }^{28}$ The formal coordination of the metal is then larger than 3, but the trigonal-pyramidal $\mathrm{MCl}_{3}{ }_{3}^{-}$ moiety can still be recognized by the occurrence of three shorter $\mathrm{M}-\mathrm{Cl}$ bonds. In the solid state, the expansion of the coordination sphere is apparently facilitated by packing effects in the crystal lattice, while, in solution, molecular structures in accordance with the VSEPR model are favored. The preference of the coordination number 3 in solutions is also demonstrated by the fact that, upon addition of chloride to acetonitrile solutions of $\mathrm{MCl}_{3}{ }^{-}$, complexes of the type $\mathrm{MCl}_{x}(x-2)-$ with $x>3$ are not found at all $(\mathrm{M}=\mathrm{Ge}$, $\mathrm{Sn})$ or are found only as species of low stability $(\mathrm{M}=\mathrm{Pb})$. However, in contrast to $\mathrm{Ge}^{2+}$ and $\mathrm{Sn}^{2+}$, the $\mathrm{Pb}^{2+}$ ion is sufficiently large to expand its coordination sphere even in solution, although the equilibrium constant for the formation of $\mathrm{PbCl}_{4}{ }^{2-}$ is rather small. In accordance with the VSEPR model and by analogy to the isoelectronic complex ions $\mathrm{SbCl}_{4}{ }^{-}$and $\mathrm{BiCl}_{4}{ }^{-}$, it is assumed that the solution structure of $\mathrm{PbCl}_{4}{ }^{2-}$ - is of the butterfly (or seesaw) $\left(C_{2 v}\right)$ type. ${ }^{4}$

The ground-state structures of $\mathrm{MCl}_{3}{ }^{-}$and $\mathrm{MCl}_{4}{ }^{2-}$ as outlined above deviate from the highest possible symmetries (trigonalplanar, $D_{3 h}$, and tetrahedral, $T_{d}$ ) due to a second-order JahnTeller effect. ${ }^{30}$ A trigonal-planar $\mathrm{MCl}_{3}$ - complex is not stable, since the two valence electrons of the $\mathrm{s}^{2}$ ion occupy the strongly antibonding $\mathrm{a}_{1}{ }^{*}$ orbital (Figure 4 ). The distortion to a trigonalpyramidal structure $\left(C_{3 v}\right)$ leads to a stabilization of the electron pair by sp $\left(a_{1}\right)$ orbital mixing. Analogously, the tetrahedral structure of $\mathrm{PbCl}_{4}{ }^{2-}$ is not stable but is distorted to the butterfly structure. Again, the distortion is associated with a stabilization of the $\mathrm{s}^{2}$ electron pair by sp hybridization. ${ }^{4}$

However, contrary to the case of the ground states of $\mathrm{MCl}_{3}-$ and $\mathrm{MCl}_{4}^{2-}$, the stabilization of trigonal-pyramidal and butterfly structures is lost in the sp excited state, since the energy gain of the HOMO $a_{t}$ is compensated by the energy loss of the electron promoted to the LUMO $a_{1}{ }^{*}$ (Figure 4). We suggest that the sp excited complex ions relax then to the stereochemically less demanding highly symmetric trigonal-planar (Figures 4 and 5)

(27) Harrison, P. G. Coord. Chem. Rev. 1976, 20, 1

(28) Haupt, H. J.; Huber, F.; Sandbote, H.-W. Z. Anorg. Allg. Chem. 1977, $435,191$.

(29) Poulsen, F. R.; Rasmussen, S. E. Acta Chem. Scand. 1970, 24, 150

(30) Albright, T. A.; Burdett, J. K. Whangbo, M.-H. Orbital Interactions in Chemistry; Wiley: New York, 1985

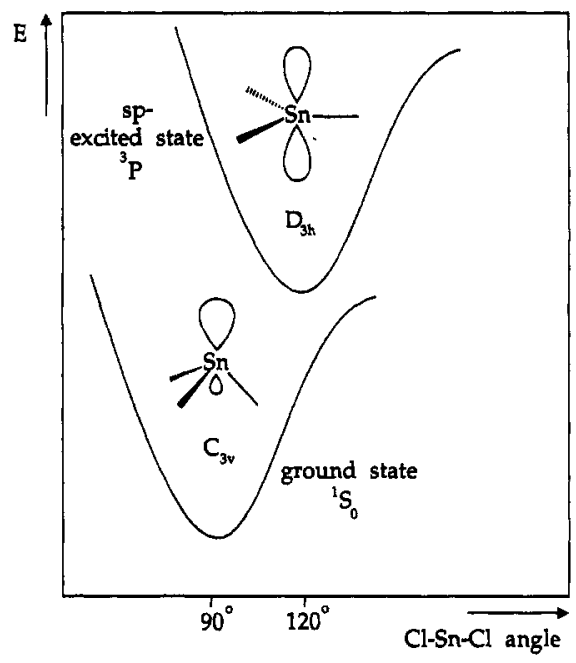

Figure 5. Qualitative potential energy diagram of $\mathrm{SnCl}_{3}-$.

and tetrahedral structures. ${ }^{4}$ The rather large Stokes shift which we observed for $\mathrm{MCl}_{3}{ }^{-}$and $\mathrm{MCl}_{4}{ }^{2-}$ is certainly caused by the elimination of the ground-state distortion in the excited state.

Our suggestion that the distortion of $\mathrm{s}^{2}$ metal complexes is eliminated by sp excitation is not a completely new idea. A similar approach has been used before to explain the large Stokes shift of $s^{2}$ ions doped into solid matrices. In the ground state, the $\mathrm{s}^{2}$ ions can occupy off-center positions in large interstices formed by the anions, but in the sp excited state, they move toward the center. ${ }^{20}$

In this context, it is quite interesting to note that the Stokes shift observed for many transition metal complexes is caused by an opposite effect. While $\mathrm{d}^{n}$ metal complexes are mostly rather symmetrical in their ground states, they frequently undergo a distortion in the excited state. ${ }^{1}$

Finally, the origin of the luminescence quenching of $\mathrm{MCl}_{3}$ and $\mathrm{MCl}_{4}{ }^{2-}$ by oxygen should be briefly discussed. $\mathrm{Sn}^{2+}$ has been known for a long time to undergo a facile photooxidation to $\mathrm{Sn}^{4+}$ by oxygen. ${ }^{3,15}$ Because of its potential application for electroless metal plating, this photoreaction was studied in some detail.14 However, the nature of the reactive excited state was apparently not of any interest. In addition to $\mathrm{Sn}^{2+}$, other $\mathrm{s}^{2}$ ions such as $\mathrm{Tl}^{+}{ }^{31}$ and $\mathrm{Sb}^{3+6}$ are also photooxidized in the presence of oxygen. It has been shown only recently that the photooxidation of $\mathbf{S b}^{3+}$ to $\mathrm{Sb}^{5+}$ is caused by an excited-state electron transfer from $\mathrm{Sb}^{3+}$ to $\mathrm{O}_{2}{ }^{6}$ Although the investigation of the photochemistry of the ions $\mathrm{MCl}_{3}{ }^{-}$was not within the scope of the present work, we note that $\mathrm{SnCl}_{3}{ }^{-}, \mathrm{GeCl}_{3}{ }^{-}$, and, with much smaller efficiency, also $\mathrm{PbCl}_{3}{ }^{-}$ underwent a photooxidation by oxygen ${ }^{32,33}$ It is assumed that these reactions occur by an excited-state electron transfer in analogy to the $\mathrm{Sb}^{3+}$ reaction.

\section{Conclusion}

Chloro complexes of $\mathrm{s}^{2}$ ions such as $\mathrm{GeCl}_{3}, \mathrm{SnCl}_{3}{ }^{-}, \mathrm{PbCl}_{3}{ }^{-}$, and $\mathrm{PbCl}_{4}{ }^{2-}$ are luminescent under ambient conditions. While these complex ions have less symmetrical structures in their ground states in accordance with the VSEPR model, it is suggested that these complexes rearrange toward highly symmetrical geometries in the emitting metal-centered sp excited states.

Acknowledgment. Support of this research by the Deutsche Forschungsgemeinschaft (Grant Vo 211/8-1) and BMFT (Grant $0329075 \mathrm{~A}$ ) is gratefully acknowledged. We thank P. Huber for emission lifetime measurements.

(31) (a) Kirkbright, G. F.; West, T.S.; Woodward, C. Talanta 1965, 12, 517 (b) Kirkbright, G. F.; Mayne, P. J.; West, T. S. J. Chem. Soc., Dalton Trans. 1972, 1918

(32) Becht, A. Diploma Thesis, University of Regensburg, 1990

(33) Nikol, H. Unpublished results. 